\title{
Using Webquest As A Universal Design For Learning Tool To Enhance Teaching And Learning In Teacher Preparation Programs
}

Chien-Hui Yang, National Institute of Education, Nanyang Technological University, Singapore Pei Wen Tzuo, National Institute of Education, Nanyang Technological University, Singapore

Cecile Komara, University of Alabama, USA

\begin{abstract}
Developed by Dodge (1995), WebQuest is an inquiry-based teaching tool, in which students of all ages and levels participate in an authentic task that use pre-designed, pre-defined internet resources, though other print resources can also be used. Learners will put the focus on gathering, summarizing, synthesizing, and evaluating the information within clearly defined parameters in order to accomplish an authentic task set by the instructor. WebQuest takes a problem-solving approach and exhibits a clear structure that guides the learning processes and interactions (Dodge, 2001), and can be used for different subject areas across age levels, from young children to adult learners (Ezell, Klein, Hines, \& Hall, 2003). In teacher preparation, research has shown that WebQuest enhanced problem-solving skills, higher order thinking, motivation, creativity, critical thinking, active learning, connection to authentic contexts (Abu-Elwan, 2007; Allan \& Street, 2007; Lim \& Hernandez, 2007) and assisted in bridging the theory to practice gap (Lim \& Hernandez, 2007). It should be noted that most studies were conducted on the subject areas of Math, literacy, or science. In Singapore context, many local teachers still haven't heard of WebQuest and learned about using WebQuest in their teaching. Further, few research studies have focused on establishing WebQuest as an evidence-based practice in enhancing teaching and learning or a pedagogy promoting Universal Design for Learning and inquiry based learning. This research project intends to introduce WebQuest, to be modelled and integrated in a course training special education pre-service teachers (allied educators) in Singapore. Specifically, the following research questions were posed: (1) Does the use of WebQuest in teacher preparation promote special education teachers' understanding on Universal Design for Learning (UDL) in accommodating students with diverse learning needs? (2) Does WebQuest a useful tool to enhance teacher's higher order thinking, engagement, creativity, and collaborative learning skills? (3) Does the use of WebQuest in teacher preparation foster stronger desires for teachers to integrate ICT in teaching and learn more about WebQuest? Forty one teacher responded to a survey questionnaire after experiencing WebQuest developed by the course instructor in teacher preparation program. Teachers also learned about WebQuest as an Universal Design for Learning tool for students with diverse learning needs. The majoirty of teachers indicated strong favors over WebQuest activities over traditional teacher-directed learning methods. All participants found WebQuest helpful in accommodating individual differences and learning styles (Agree: 68.3\%; Strongly agree: 31.7\%). Forty teachers $(N=41)$ reflected that they used more critical thinking and problem solving skills when they engaged in the WebQuest activities developed by the instructor (39\% strongly agree and 56.1\% agree). Thirty nine teachers agreed that they were required to use more creativity when they engaged in the WebQuest activities $(24.4 \%$ of teachers stronly agree and $68.3 \%$ agree). The majority of teachers $(26.8 \%$ strongly agree and $68.3 \%$ agree) felt that they know more about ways to incorporate technology for teaching and learning after experiencing WebQuest in this class. They also indicated that they would like to use more technology and web resources in teaching in the future after learning about WebQuest (41.5\% strongly agree and $53.7 \%$ agree).
\end{abstract}

Keywords: WebQuest, research projects, teacher preparation.

\section{INTRODUCTION}

\subsection{Background}




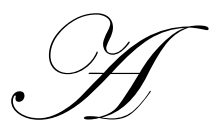

dvances in modern technology combined with increased accessibility has made technology the most dominant contributor to society in the $21^{\text {st }}$ century. In the United States, $87 \%$ of young people aged 12-17 use the internet, and more than 50\% of these learners create content online, such as web pages or blogs (Lenhart, Madden, Macgill, \& Smith, 2007). More than $70 \%$ of 4 year olds have used a computer (Fisch \& McLeod, 2007). In a highly modern and technology-focused nation like Singapore, one can assume that these statistics would likely exceed the attributes of U.S. numbers. According to Marc Prensky (2001), today's learners are defined as "digital native" because they were born into the high-tech digital ages and surrounded by computers, internet, online social network, cell phones, and video games. They think and process information differently than the previous generations of "digital immigrants", a generation of individuals who were not born into the digital ages but had to learn to use and cope with the advances of technology in the midst of their career (Prensky, 2001). "The single biggest problem facing education today is that our Digital Immigrant instructors, who speak an outdated language (that of the pre-digital age), are struggling to teach a population that speaks an entirely new language" (Prensky, 2001, p.2). Indeed, as the technology advances in all aspects of our daily lives, our education system is often slow to adapt and change. The generation gap between "digital native" and "digital immigrant" can be manifested in how teachers and students interact and engage in teaching and learning in our classrooms, from kindergarten through higher education, and even into teacher preparation programs. It is a major concern whether the needs of "digital natives" can be met by educators who are largely "digital immigrants". In K12 education, research has shown that teachers do not regularly use technology during their teaching or integrate technology in their classrooms (Bielefeldt, 2001; Wang, Ertmer, \& Newby, 2004). Under the current trend of globalization and economic dynamics, accountability of our educational systems is being seriously tested. The essential question posed is, are our teachers and schools ready to carry out the mission to meet the demands of the future by preparing our young learners with the knowledge, skills, and innovation capabilities necessary to advance our competitiveness globally?

One powerful solution to bridge this worrisome generational gap, as the Ministry of Education (MOE) in Singapore has wisely proposed, is the use of Information and Communication Technology (ICT) to improve teaching and learning to enhance the competitiveness of our future work force. The other is to increase the competitiveness of workforce by emphasizing inquiry-based learning, higher order thinking, and problem solving. This study asserts that these two goals, rather than being mutually exclusive, are indeed highly related. After all, research has shown that integrating technology in teaching and learning can have positive influences on students' motivation, inquiry-based learning, attitudes, achievement, and peer interactions in the classrooms (Schofield, 1995).

\subsection{Introduction of WebQuest:}

While the integration of technology in education is highly valued, some researchers also caution, "Technology alone does not guarantee solutions to educational problems" (Hassanien, 2006, p.42). In response to this caution, this research project proposes the use of WebQuest. WebQuest demonstrated a project-based learning that helps students to complete authentic projects integrating technology in their learning (Garry, 2001). Developed by Dodge (1995), WebQuest is an inquiry-based teaching tool, in which students of all ages and levels participate in an authentic task that use pre-designed, pre-defined internet resources, though other print resources can also be used. Learners will put the focus on gathering, summarizing, synthesizing, and evaluating the information within clearly defined parameters in order to accomplish an authentic task set by the instructor. WebQuest takes a problemsolving approach and exhibits a clear structure that guides the learning processes and interactions (Dodge, 2001), and can be used for different subject areas across age levels, from young children to adult learners (Ezell, Klein, Hines, \& Hall, 2003). Research has documented that WebQuest has effectiveness in promoting student engagement, motivation, connecting to authentic contexts, critical thinking, higher order thinking, literacy skills, and Information and Communication technology (ICT) integration (Abbitt \& Ophus, 2008; Ikpeze \& Boyd, 2007; Kanuka, Rourke, \& Laflamme, 2007).

Please refer to the following link for features and a sample lesson (http://projects.edtech.sandi.net/Valencia/puppetplay). 


\subsection{WebQuest: Theoretical Bases and Congruency with Pedagogical Approaches}

The uniqueness of WebQuest can be explained by its congruency with a broad range of learning theories and pedagogical approaches.

\subsubsection{Constructivism and Inquiry-Based Learning}

WebQuest, rooted in Constructivism, is an inquiry-based activity. WebQuest applies a constructivism learning approach that allows learners to engage in higher order thinking skills and to build meaningful learning experiences in meaning making (Lahaie, 2008). As Bennett (2001) asserted, "With the inclusion of technology into learning environments, the role of the teacher changes from instructor to guide. The learning process has become inquiry based. The instruction is student centered and the learner is actively engaged" (p. 9). WebQuest promotes inquiry-based learning by assisting learners to organize ideas, explore and evaluate information, analyze and synthesize data, and communicate findings and conclusions (Lamb \& Teclehaimanot, 2005).

\subsubsection{Higher order thinking and Problem solving}

Higher order thinking and learning can be viewed as an ability to compare, explain, contrast, analyze, apply, theorize, generalize, hypothesize, and reflect (Biggs, 2003). The benefit of WebQuest in promoting higher order thinking skills is commonly recognized (Allen \& Street, 2007; Lara \& Reparaz, 2005; Lim \& Hernadez, 2007; Rickards, 2005). Gohagan (2000) asserted that WebQuest improves learners' problem solving skills by requesting learners to expand and refine their knowledge, and integrate their skills in order to accomplish an authentic task. While WebQuest offers authentic learning tasks for learners, resources and processes in accomplishing tasks are provided, but there is no one correct way to complete the task. Consequently, students are required to find their own paths based on their learning preferences, goal setting, and individual differences to achieve the task, which is a great opportunity for problem solving and higher order thinking. Participants in one study asserted that the most meaningful part of WebQuest experiences was having the opportunities to develop critical thinking and creativity (Lim \& Hernadez, 2007). Research has shown that WebQuests were more effective than some other activities at supporting a higher cognitive presence and thinking compared to other strategies (Kanuka, Rourke, \& Laflamme, 2007). Moreover, while WebQuest is used in junction with cooperative learning approaches as this project proposes, the problem solving skills of learners can be further enhanced (Lara \& Reparaz, 2005).

\subsubsection{Universal Design for Learning and Differentiated Instruction}

While the principle of Universal Design is widely used in Architecture (e.g., the use of automatic doors to make buildings accessible for individuals with different mobility abilities), the application of these principles in the form of Universal Design for Learning (UDL) in education is fairly recent (Council for Exceptional Children, 2005; Rose \& Meyer, 2002; Rose, Meyer, \& Hitchcock, 2005). Derived from neuroscience and the advanced knowledge of individual differences, Universal Design for Learning (UDL) is intended to design curriculum in ways that accommodate all learners with different learning styles, ability levels, backgrounds, and preferences (Rose \& Meyer, 2002). As a blueprint for teaching every student, Universal Design for Learning features the following three principles: (1) multiple means of representation of information and concepts, (2) multiple means of engagement of learners, and (3) multiple means of expression and performance (Rose \& Meyer, 2002). To implement UDL, teachers are to change their way of teaching by offering multiple ways to present the content knowledge, promoting student engagement, and offering alternative methods for students to express what they have learned. Examples of UDL teaching tools include but not limited to: WebQuest, guided notes, portfolio, graphic organizers, text to speech synthesizer, and tiered assignments. It is realized that UDL can benefit all types of learners with high, average, and low abilities.

\subsection{WebQuest: Research and Application}

A recent search of the webquest.org database showed more than 1700 user-contributed WebQuest activities in all K-12 curricular areas as well as materials for adult learners and higher education. It should be noted that compared to the large number of user-contributed WebQuest activities on the internet, in the literature, the number 
of research studies on WebQuest is significantly smaller. At K-12 levels, research has shown that WebQuest benefited students' engagement, higher order thinking, motivation, connection to authentic contexts, critical thinking, problem solving, collaborative learning, and literacy skills (Ikpeze \& Boyd, 2007; Lara \& Reparaz, 2005). In teacher preparation, research has shown that WebQuest enhanced problem-solving skills, higher order thinking, motivation, creativity, critical thinking, active learning, connection to authentic contexts (Abu-Elwan, 2007; Allan \& Street, 2007; Lim \& Hernandez, 2007) and assisted in bridging the theory to practice gap (Lim \& Hernandez, 2007). It should be noted that most studies were conducted on the subject areas of Math, literacy, or science.

\subsection{Relevance to Special Education Teacher Preparation}

\subsubsection{Disciplinary Specific Emphases}

Because of its congruency with a broad range of learning theories, WebQuest is highly relevant to the curricular specific objectives in Special Education. For special education teachers, Universal Design for Learning (UDL) has become an emphasis in improving the performance of students with special needs (Hitchcock \& Stahl, 2004). UDL provides an alternative to the teacher-centered traditional methods by guiding teachers to adapt curriculum and instruction to maximize students' access to the general education curriculum and opportunities to succeed (Pisha \& Coyne, 2001). Research has shown that UDL improved students' engagement in subject areas for typical students, as well as students with disabilities (Kortering, McClannon, \& Braziel, 2008).

\subsubsection{Teach What We Preach: Recommended Practices}

This study argues that in order to ensure pre-service and in-service teachers achieve curricular specific goals (such as inquiry based learning, higher order thinking, collaborative learning, Universal Design for Learning), instructors in teacher preparation programs must teach and model what we preach for two reasons. First, when the instructors model the recommended practices and instructional strategies, K-12 teachers have opportunities to observe these practices at work, which may in turn enhance their understanding and skills in application of the teaching practices. Second, K-12 teachers have opportunities to experience the benefits of implementing the recommended practices as learners, in comparison to traditional teacher-directed paper-pencil teaching methods. The positive learning experiences may motivate them to adopt the recommended practices and strategies in their classrooms. These arguments are in sync with Confucius' famous saying, "I hear and I forgot, I see and I remember, I do and I understand."

\subsubsection{Modeling for ICT integration}

The literature strongly supports the importance of modelling the use of technology by instructors in higher education and teacher preparation programs (Widmer \& Amberger, 1994). Research has shown that when teachers were exposed to the use of technology in teacher preparation courses, they were more likely to use the technology in K-12 classrooms and developed more positive attitudes toward integrating technology into their teaching (Gulbahar, 2008; Wheatly, 2003). On the contrary, lack of use and integration of technology in teacher preparation programs can result in technology anxiety of pre-service and beginning teachers (Wild, 1996). This study offers teachers opportunities to interact with web resources and use technology through WebQuest activity, which may promote ICT integration in their teaching.

\subsection{Singapore Context}

\subsubsection{Relevance to MOE Goals and Directions}

Singapore's Ministry of Education (MOE) has launched important initiatives to anticipate the needs of the future and to prepare our young generation to meet those needs. Examples of these initiatives include: Information and Communication Technology (ICT) mater plans, the FutureSchools@Singapore programme, Thinking Schools Learning Nation (TSLN), and Students' Effective Engagement and Development (SEED). The mater plans for Information and Communication Technology (ICT) in education are intended to strengthen the integration of ICT into curriculum and instruction, provide practice-based professional development in ICT, and distribute best 
practices and successful innovations. Under the collaboration of Ministry of Education (MOE) and Infocomm Development Authority of Singapore (IDA), several consortia have been selected to design and deploy next generation infocomm-enabled solutions for selected FutureSchools, with an emphasis on problem-based, inquirybased authentic learning through the integration of technology in teaching and learning. In addition, initiatives such as Thinking School Learning Nation (TSLN) and Students' Effective Engagement and Development (SEED), aim to enhance hands-on learning and the quality of teaching and student engagement in Singapore. These initiatives prompted teachers to move away from the traditional teacher-directed paper-pencil teaching methods. Rather, inquiry-based learning, higher order thinking, hands-on learning are set as the future direction of education and strongly encouraged.

In spite of MOE's efforts in promoting higher order thinking and inquiry-based learning, Singapore has not met the goal of transiting into an inquiry-based learning country (Tan \& Ng, 2005). Several studies suggested that teachers faced the dilemma of preparing children to perform well on traditional paper-pencil examinations, plus meeting the demands of MOE initiatives in promoting higher order thinking, problem-solving, and hands-on learning (Dixon et al., 2008; Wright \& Gan, 2006). The evidence above further stresses the importance of conducting this research project to model inquiry-based learning and promote higher order thinking for K-12 teachers. It is difficult to change the way teachers teach without the opportunities to observe new teaching practices at work. If inquiry-based learning and higher order thinking is demonstrated in teacher preparation courses, K-12 teachers will get a chance to embrace these practices as a natural way of teaching and learning, rather than hypothetically, as exists only in theory and textbooks. Moreover, Universal Design for Learning and WebQuest strategy helps teachers to accommodate students with different learning styles and special needs in the general education classrooms. These strategies are crucial content knowledge for all K-12 teachers to acquire, so that they can develop disability-awareness, respect for individual differences, and better readiness to include students with special needs in their classrooms. Again, without teaching what we preach, instructors in teacher preparation programs can't effectively improve K-12 teaching practices by promoting higher order thinking and accommodating students with special needs in general education classrooms.

Many Singapore teachers were introduced to WebQuest at the ICET conferences (2004), though few research studies have focused on establishing WebQuest as an evidence-based practice in enhancing teaching and learning or a pedagogy promoting Universal Design for Learning and inquiry based learning. Examples of exceptions investigating the use of WebQuest in Singapore local contexts include studies and papers developed by Chang (2004), Kheng (2003), and Lim (2006). While Kheng's (2003) and Lims' (2006) papers simply served as the introduction of the WebQuest as a teaching tool, Chang's (2004) paper reported a research study at the local context. Chang (2004) used WebQuest in Secondary school geography in Singapore to enhance student motivation and project based learning. Chang's study has revealed mixed results and was non-conclusive. These papers strongly signal the need for empirical research on WebQuest in Singapore local contexts, due to the limited number of research conducted and the need to validate the effects of WebQuest as an teaching strategy that promotes higher order thinking.

\subsubsection{Special Education Teacher Preparation in Singapore}

In Singapore, the teacher training is predominantly provided by National Institute of Education (NIE) at Nanyang Technological University. NIE is the only tertiary institute for preparing teachers for public schools and government-funded special education schools. Most students with special needs (particularly those with moderate to severe disabilities) attended government funded special education schools while some students with mild disabilities (particularly those with mild learning disabilities, mild Autism, or behavioural issues) attended mainstream schools. An unpublished Ministry of Education document (2004, cited in Heng \& Tam, 2006) estimated that at least 5 percent of the student population in mainstream primary and secondary schools are students with learning difficulties (such as dyslexia), attention deficit hyperactivity disorder (ADHD), and Autism.

The special education teachers in Singapore include special education teachers who work in self-contained classrooms for the special education schools or agencies, and allied educators who work in mainstream public schools. Starting 2005, Ministry of Education in Singapore developed "Special Needs Officers" (SNOs) to work with students with special needs in mainstream settings. SNOs are trained in the Diploma in Special Education 
(DISE) programme at National Institute of Education (NIE). In 2009, MOE enhanced the professional status and renamed SNO to "Allied Educator (Learning and Behavioural Support) (AED-LBS)." The allied educators are responsible for providing pull out instruction to students with special needs in mainstream schools, as well as inclass assistance to classroom teachers. The status and duties of AED-LBSs seem to be equivalent of paraprofessionals in the United States, although the term 'paraprofessional' is not used in the Singapore context. However, certain aspects of responsibilities (such as pull out instruction for students with special needs and curriculum modification) can be compared to that of special education teachers.

This research study was conducted in a course within DISE programmes at NIE training AED-LBS. In this paper, the term "special education teachers" is used to describe AED-LBS since special education teachers is more so a common term in the discipline internationally.

\section{RESARCH METHODS}

\subsection{Research Questions}

Three research questions were posed in this study: (1) Does the use of WebQuest in teacher preparation promote special education teachers' understanding on Universal Design for Learning (UDL) in accommodating students with special needs? (2) Does WebQuest a useful tool to enhance teacher's higher order thinking, engagement, creativity, and collaborative learning skills? (3) Does the use of WebQuest in teacher preparation foster stronger desires for teachers to integrate ICT in teaching and learn more about WebQuest?

\subsection{Participants}

This research study was conducted in a course within DISE programmes at NIE training AED-LBS. Forty one special education teachers (AED-LBSs) at NIE were recruited to participate in this study. Students are exposed to WebQuest activities developed by the instructor as part of their learning in a course "Sensory and Motor difficulties".

\subsection{Procedures and Instrumentation}

The instructor (author of the paper) modelled the use of WebQuest in teaching and developed a WebQuest in teacher training. Elements of the WebQuest include introduction, tasks, processes, resources (web and print resources), and evaluation. Three authentic tasks incorporating internet resources were posed as class activities: (1) Task 1: Meet Ashley. In class, you will be watching video clips of Ashley, an individual with hearing impairment and learn about her life story, and conducting a case study discussion. (2) Task 2: Learn to finger spell your name (using online finger spelling dictionary) and show it to your classmates. Discuss the adaption for children who have difficulty learning complete signs or finger spelling. (3) Task 3: Conduct a debate on deaf culture and cochlear implant in collaborative learning groups after learning the contraversy through online resources. These WebQuest activities were conducted over a period of three-weeks. At the end of the WebQuest activities, teachers were asked to complete a survey questionnaire on their learning and reflection of WebQuest. The survey contained 20 questions using a 4 point rating scale (strongly agree, agree, disagree, and strongly disagree). The data collected in the study was then compiled into the SPSS software. The percentage of each rating for each question is calculated and reported.

\section{$3 \quad$ RESULTS AND DISCUSSIONS}

Among 41 participants, 32 are female and 9 are male teachers. In terms of ethnical background, $46.3 \%$ of teachers are Chinese, 26.8\% are Malay, $14.6 \%$ are Indian, $4.9 \%$ are mixed races, and $7.3 \%$ are others (such as Javanese and Sri Lankan).

First, this study was interested in investigating teachers' internet use since literature has shown that teachers do not use technology in teaching regularly. While being asked the purposes of teachers' Internet use and to check all answers applied, the top three purposes of Internet use for pre-service teachers respectively are "Google 
and seek information" (82\%), "News and entertainment (e..g, movies, video games)" (65.9\%), and "Social Net working" (61\%). More than one third of teachers (34.1\%) also use internet for teaching purposes. While over $80 \%$ of teachers use Internet to seek information and are comfortable obtaining information via web sources, only $34.1 \%$ the teachers use Internet in their teaching. There is a great potential to motivate and train teachers to incorporate Technology in their teaching.

Second, in response to the research questions posed to this study, research findings are summarized below.

(1) Does the use of WebQuest in teacher preparation promote special education teachers' understanding on Universal Design for Learning (UDL) in accommodating students with special needs?

All participants found WebQuest helpful in accommodating individual differences and learning styles (Agree: $68.3 \%$; Strongly agree: $31.7 \%$ ). When asked whether WebQuest should be taught in teacher preparation programmes as a teaching tool for accommodating individual differences, $2.4 \%$ of teachers (1 participant out of 41 ) disagree whereas $36.6 \%$ of teachers strongly agree and $58.5 \%$ of teachers agree. In other words, special education teachers approved the value of teaching special education teachers to use WebQuest as a Universal Design for Learning tool for students with diverse learning styles and learning needs. Utilizing WebQuest to achieve curricular objective in special education was found to work based on teachers' ratings.

(2) Does WebQuest make a useful tool to enhance teacher's higher order thinking, engagement, creativity, and collaborative learning skills?

Forty teachers $(\mathrm{N}=41)$ reflected that they used more critical thinking and problem solving skills when they engaged in the WebQuest activities developed by the instructor (39\% strongly agree and $56.1 \%$ agree). Thirty nine teachers agreed that they were required to use more creativity when they engaged in the WebQuest activities (24.4\% of teachers stronly agree and $68.3 \%$ agree). In addition, $29.3 \%$ of teachers strongly agreed and $68.3 \%$ of teachers agree that WebQuest activities allowed them to be more motivated in learning and more engaged to a deeper level. Regarding collaborative learning, $41.5 \%$ of teachers strongly agree and $56.1 \%$ of teachers agree that WebQuest helped them learn from each other, work together, and problem solve. It sould be noted that only 1 teacher did not agree that WebQuest promoted engagement and collaborative learning. It would be interesting to conduct follow up interview with that particular teacher and hear his/her input.

Overall, after experiencing WebQuest activities, teachers felt that WebQuest promoted higher order thinking, critical thinking, problem solving, engagement and understanding, and collaborative learning. Once teachers experienced how WebQuest had facilitated their learning as learners, the next question would be, would teachers then become more interested and keen to integrate WebQuest and ICT in their teaching?

(3) Does the use of WebQuest in teacher preparation foster stronger desires for teachers to integrate ICT in teaching and learn more about WebQuest? After experiecning WebQuest in this course, the majority of teachers (26.8\% strongly agree and $68.3 \%$ agree) felt that they learned more ways to incorporate technology for teaching and learning. They also indicated that they would like to use more technology and web resources in their teaching in the future (41.5\% strongly agree and $53.7 \%$ agree). All teachers agreed that they would like to learn to develop a WebQuest for their stuents in P/K-12 classrooms if given support, time and guidance to do so (48.8\% strongly agree, and $51.2 \%$ agree).

This study revealed promising results using WebQuest in special education teacher preparation in Singapore. Future revisions on the instrucment are recommended to investigate the challenges and barriers teachers face in the process of learning WebQuest. It would be valuable to further encourage teachers to use WebQuest in $\mathrm{P} / \mathrm{K}-12$ classrooms for students with diverse learning needs and conduct sub-studies on the implication of WebQuest in $\mathrm{P} / \mathrm{K}-12$ levels. The limitation of the study is the small sample size $(\mathrm{N}=41)$. Thus simliar studies of larger scope are needed to draw stronger conclusions and make generalizations. 


\section{AUTHOR INFORMATION}

Chien-Hui is an assistant professor at National Institute of Education (NIE), Nanyang Technological University, Singapore. She obtained her doctorate in Early Childhood Special Education at University of Kansas at the United States. Chien-Hui taught at the Missouri State University at the United States for 3 years before joining NIE in 2005. Her research interests include early intervention, e-learning, ICT integration in education and teacher preparation, inclusion, teacher training, evidence based practices, and early childhood education. She has several research grants focusing on ICT integration in education and teacher preparation, early childhood education, and early intervention.

Pei-Wen Tzuo is currently an assistant professor of Early Childhood and Special Needs Education at the National Institute of Education in Singapore. She received her Ph.D. from Indiana University- Bloomington in the US in 2004. After that, she returned to Taiwan where she taught in a reputed teacher education program before moving to Singapore. Her research interests include issues and trends of teacher education as well as globalization and diversity in education.

Cecile has a Ph.D. in Special Education from the University of Kansas. She is an assistant professor at the University of Alabama teaching courses in early childhood special education (ECSE) and is the ECSE program coordinator. Her research interests include technology use in teacher preparation courses, technology use in the classroom, and mathematics in the prekindergarten classroom.

\section{REFERENCES}

1. Abu-Elwan, R. (2007). The use of WebQuest to enhance the Mathematical Problem-Posing skills of preservice teachers. International Journal for Technology in Mathematics Education, 14(1), 31-39.

2. Allen, J., \& Street, M. (2007). The quest for deeper learning: An investigation into the impact of a knowledge-pooling WebQuest in primary initial teacher training. British Journal of Educational Technology, 38(6), 1102-1112.

3. Lim, S., \& Hernandez, P. (2007). The WebQuest: An illustration of instructional technology implementation in MFT training. Contemporary Family Therapy, 29, 163-175.

4. Lenhart, A., Madden, M., Macgill, A. R., \& Smith, A. (2007). The use of social media gains a foothold in teen life as they embrace the conversational nature of interactive online media. Pew Internet \& American Life Project. Retrieved March 19, from http://www.pewinternet.org

5. Fisch, K., \& McLeod, S. (2007). Did you know? Retrieved March 19, 2009, from http://www.youtube.com

6. Prensky, M. (2001). Digital natives, digital immigrants. On the Horizon, 9(5). Retrieved March 19, 2009, from http://www.marcprensky.com/writing/Prensky\%20\%20Digital\%20Natives, \%20Digital\%20Immigrants\%20 -\%20Part1.pdf

7. Bielefeldt, T. (2001). Technology in teacher education. Journal of Computing in Teacher Education, 17(4), 4-15.

8. Wang, L., Ertmer, P. A., \& Newby, T. J. (2004). Increasing pre-service teachers' self-efficacy beliefs for technology integration. Journal of Research on Technology in Education, 36(3), 231-250.

9. Schofield, J. W. (1995). Computers and classroom culture. New York: Cambridge University Press.

10. Garry, G. (2001). Project-based learning just became easy: an introduction to WebQuest. Learning Technology, 3(3). Retrieved March 19, 2009, from http://lttf.ieee.org/learn tech/issues/july2001/index.html

11. Dodge, B. (1995). Some thoughts about WebQuests. Retrieved March 19, 2009, from http://webquest.sdsu.edu/about_webquests.html

12. Dodge, B. (2001). Five rules for writing a great WebQuest. Learning and Leading with Technology, 28(8), 6-9.

13. Ezell, D., Klein, C., Hines, R., \& Hall, S. (2003). Using WebQuest with students with disabilities, Center on Disabilities. Paper presented at Technology and Persons with Disabilities Conference. Retrieved March 19, 2009, from http://www.csun.edu/cod/conf/2003/proceedings/104.htm 
14. Abbitt, J., \& Ophus, J. (2008). What we know about the impacts of WebQuests: A review of research. AACE Journal, 16(4), 441-456.

15. Ikpeze, C. H., \& Boyd, F. B. (2007). Web-based inquiry learning: Facilitating thoughtful literacy with WebQuests. The Reading Teacher, 60(7), 644-654.

16. Kanuka, H., Rourke, L., \& Laflamme, E. (2007). The influence of instructional methods on the quality of online discussion. British Journal of Educational Psychology, 38(2), 260-271.

17. Lahaie, U. D. (2008). Is nursing ready for WebQuest? Journal of Nursing Education, 47(12), 567-570.

18. Lamb, A., \& Teclehaimanot, B. (2005). A decade of WebQuests: A retrospective. In M. Orey, J. McClendon, \& R. M. Branch (Eds.), Educational media and technology year book (Vol. 30, pp. 81-101). Westport, CT: Libraries Unlimited.

19. Biggs, J. (2003). Teaching for quality learning at university ( $2^{\text {nd }}$ ed.). Buckingham, UK: The Society for Research into Higher Education and Open University Press.

20. Lara, S., \& Reparaz, Ch. (2005). Effectiveness of cooperative learning: WebQuest as a tool to produce scientific video. Retrieved March 19, 2009, from http://www.formatex.org/micte2005

21. Lim, S., \& Hernandez, P. (2007). The WebQuest: An illustration of instructional technology implementation in MFT training. Contemporary Family Therapy, 29, 163-175.

22. Richards, C. (2005). The design of effective ICT-supported learning activities: Exemplary models, changing requirements, and new possibilities. Language, Learning and Technology, 9(1), 60-79.

23. Council for Exceptional Children. (2005). Universal Design for Learning: A guide for teachers and education professionals. Arlington, VA: Council for Exceptional Children.

24. Rise, D. H., \& Meyer, A. (2002). Teaching every student in the digital age: Universal Design for Learning. Alexandria, VA: The Association for Supervision and Curriculum Development.

25. Rise., D. H., Meyer, A., \& Hitchcock, C. (Eds.). (2005). The universally designed classroom: Access curriculum and digital technologies. Cambridge, MA: Harvard Education Press. 


\section{NOTES}

